\title{
CHARACTERIZATION OF SIDE LOAD PHENOMENA USING MEASUREMENT OF FLUID/STRUCTURE INTERACTION
}

\author{
Dr. Andrew M. Brown*, Joseph Ruf*, Darren Reed*, Mark D'Agostino* \\ NASA/Marshall Space Flight Center, MSFC, AL 35812 \\ Dr. Russell Keanini \\ Department of Mechanical Engineering, University of North Carolina at Charlotte, Charlotte, NC 282223
}

\begin{abstract}
$\underline{\text { Abstract }}$
During ground-tests of most production rocket engines over the last 30 years, large asymmetric transient side loads coming from the nozzle and related steady-state vibrational loads within the nozzle have been measured. The widely varying magnitude of these loads has been large enough to fail interfacing components as well as nozzles in these engines. This paper will discuss a comprehensive test and analysis program that has been undertaken to develop a methodology to accurately predict the character and magnitude of this loading. The project to-date has incorporated analytical modeling of both the fluid flow and the nozzle structure and testing of both full-scale and sub-scale rocket nozzles. Examination of the test data indicates that one of the two-nodal diameter structural modes may be interacting with flow separation from the nozzle inside-wall in a selfexcited or aeroelastic vibration phenomenon. If verified, this observation will be used to develop a methodology for design and analysis. A fuller understanding of the characteristics of this vibration will provide an increase in the accuracy and confidence of side load predictions, which will be critical for the successful construction of the next generation of low-cost, reliable rocket engines.
\end{abstract}

\section{Background}

There has been widespread recognition of the importance of the side load phenomena since large rocket engines have been built. Work on shockinduced boundary layer separation within overexpanded rocket nozzles, and on the role of separation in rocket nozzle side loads, appears to have been initiated in the late 1940's at JPL and Caltech ${ }^{1,2}$.These and subsequent investigations, carried out in the $1950^{\circ} \mathrm{s}, 60^{\circ} \mathrm{s}$, and $70^{\circ} \mathrm{s}$, focused on determining conditions leading to boundary layer separation ${ }^{1-6}$. Some of the most detailed test data taken was on the Rocketdyne J-2 engine for the
Saturn $V$ in $1972^{7}$, which measured loads in instrumented load cells at side-arm locations and accelerations at the nozzle exit plane. Among a number of conclusions, separation was seen to occur at an axial location on the nozzle where the separation pressure ratio, which is the ratio of the wall pressure $\left(p_{w}\right)$ to the ambient pressure $\left(p_{2}\right)$, drops to a critical value of 0.285 . In addition, there was an observed interaction with the $2^{\mathrm{ND}}$, or "bell mode", of the nozzle, ${ }^{7,8}$. The bell mode, however, only becomes a problem if steady-state conditions of the firing are conducive to constant separation; otherwise, only the transient is of concern. The transient load essentially produces the asymmetric load which impacts hardware interfacing with the nozzle, while the steady-state $2^{\mathrm{ND}}$ modal response is a source of concern for the structural integrity of the nozzle itself. Both types of loading are interconnected, though, and are termed as part of the "side-load" phenomena. Most studies after the J-2 testing concentrated on the fluid dynamic aspects of the separation phenomena, with various other criteria being proposed for determining nominal separation locations ${ }^{3-6}$. Summerfield' ${ }^{3}$ well-known condition asserts that separation takes place at the point where this ratio is .40 . Arens and Spiegler ${ }^{4}$ showed that the separation pressure ratio is also dependent on upstream Mach numbers, $\mathbf{M}_{\mathbf{2}}$. Schmucker ${ }^{6}$ incorporated the effect of upstream Mach number in a relatively simple separation pressure ratio criterion that still finds wide use. Frey and Hagemann? noting that separation also depends on nozzle contour, wall roughness, and wall temperature, suggest that development of a universally applicable separation criterion may be relatively difficult.

Recent numerical and experimental work has focused on understanding fundamental flow phenomena underlying boundary layer separation within nozzles ${ }^{9-13}$. Frey and Hagemann's ${ }^{\prime}$ work examined flow structure associated with both free shock separation and restricted shock separation, where the latter, characterized by boundary layer reattachment, occurs under a relatively limited range of conditions. Chen et al. ${ }^{10}$ appear to have been the first to theoretically detail many of the shockinduced flow structures produced during start-up and throttle-down procedures, including transition between free shock and restricted shock separation. Subsequent

\footnotetext{
- Member, AIAA
} 
studies $^{11-13}$ have largely confirmed the numerical results reported by Chen et al. ${ }^{10}$. Due to the high computational cost of simulating turbulent supersonic separated flows, all models to date have been twodimensional. Thus, rigorous calculation of side loads, based on simulation of the complete threedimensional separated flow field, has not been attempted.

Due to the complexity of the forcing function, most of the research described above focused on empirically characterizing the load itself and determining how it caused the structural system to respond. For design purposes, the SSME and most other rocket engine development programs have used the J-2 data as a basis for a Monte Carlo analysis to predict the asymmetric side loads, where the random variables include the distribution of the J-2 data itself, a scaling factor on the J-2 data, and location of initial separation (both axial and circumferential) as a function of the separation ratio ${ }^{14,15}$. The Monte Carlo analysis is used since each of the variables has such a wide distribution and since it is difficult to a-priori determine the worst-case combination of the random variables. Very little work beyond derivation of empirical equations relating various flow and pressure parameters in a new engine to the transmitted load measured on the $\mathrm{J}-2$ has since been accomplished, and the interaction of the structural dynamics of the engine design with the loading has not been examined extensively. This approach has typically resulted in large uncertainties in the determination of side loads, yielding little confidence in the empirical prediction of these values, and therefore requiring extensive conservatism in the application of these loads with the accompanying weight and programmatic penalties. A recent work by Pekarri ${ }^{16}$, though, has identified the interaction of the structural response with the fluid forcing function and outlined an aeroelastic analytical methodology to examine it. For the nozzle used in his work, the fundamental mode is first bending, which would significantly add to the net effect of the transient asymmetric loading if it becomes excited. The methodology outlined by Pekarri will be applied as the next phase of the project discussed in this paper.

The indirect empirical equations referenced above were used to extrapolate a side load magnitude for loads analysis in the NASA/Marshall Space Flight Center (MSFC) FASTRAC (later renamed MC-1) engine program during 1998. Because of the uncertain nature of the calculations, several extremely conservative assumptions were used, resulting in a large value of loading. When this load was used in the engine system model, it predicted the failure of several components. In order to obtain a more reliable and less over-conservative estimate of

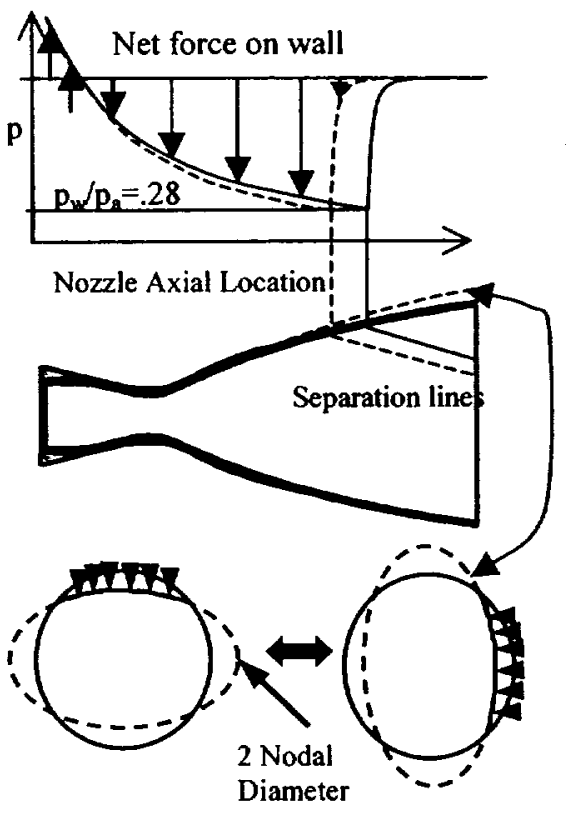

Figure 1. Hypothesized Fluid/Structure Interaction

the side load magnitude, a program was initiated to try to understand the nature of the loading itself. A hypothesis was formulated for an unstable excitation of the $2^{\mathrm{ND}}$ mode. In this hypothesis, separation initially occurs at a single circumferential location, as is indicated in video of the startup of the Space Shuttle Main Engine. The delta pressure across the nozzle wall at that location decreases dramatically from a large net external compressive pressure to a very small value (see figure 1), while the rest of the nozzle at that axial location still has a large net compressive pressure. This pressure change causes the nozzle to bow outward at that location and at the position $180^{\circ}$ from it, and causes it to deflect inward at locations $90^{\circ}$ away, following the static deflection shape resulting from a localized circumferential load on a nozzle. If the net force from the pressure change is large enough to

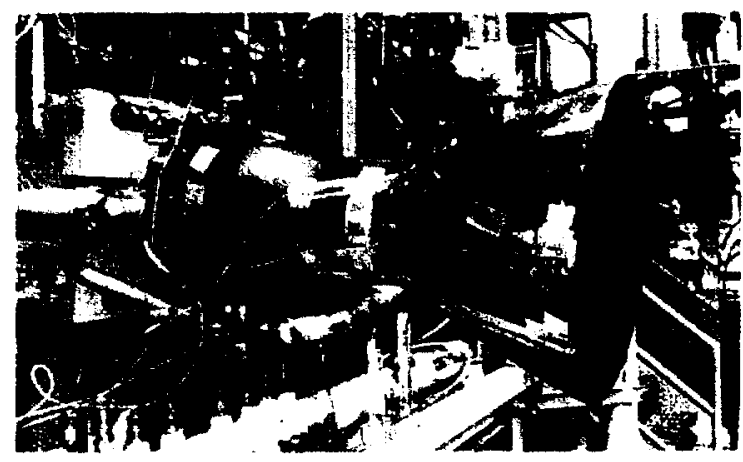

Figure 2. Instrumented FASTRAC Nozzle (stub version) 


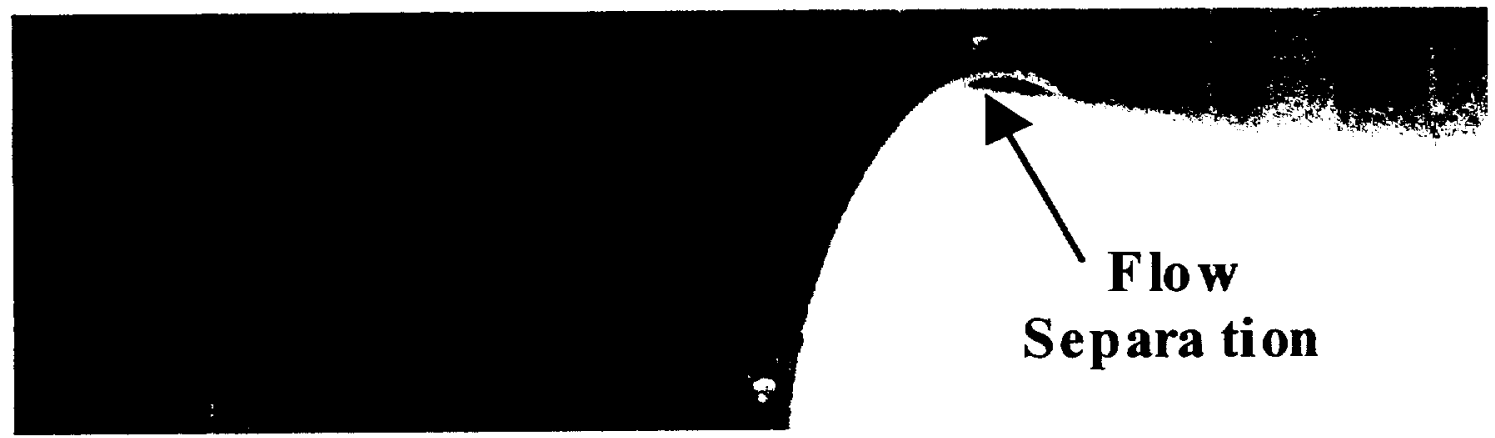

Figure 3. Flow Separation during Hot-Fire Test of FASTRAC Nozzle

cause a significant deflection, the internal pressure in the attached region upstream of the separation is driven slightly down at the initial separation location and up at the $90^{\circ}$ locations. If the critical separation pressure ratio is assumed to be constant, this causes the separation to even more preferentially choose the original location. Since this excitation occurs in a sudden manner, and the shape caused by the separation field is very similar to a $2^{\mathrm{ND}}$ structural mode, the structure starts responding dynamically in that mode shape, and initiates an unstable feedback loop.

To study this hypothesis, the first step taken was to make strain-gauge measurements on the nozzle itself during a hot-fire test (see Figure 2). The objective was to use these measurements in conjunction with the structural dynamics model to extrapolate the unknown side load. The hot-fire test took place in late 1998, and the flow separation (Figure 3 ) and the resulting data turned out to be surprisingly clean, and clearly showed the

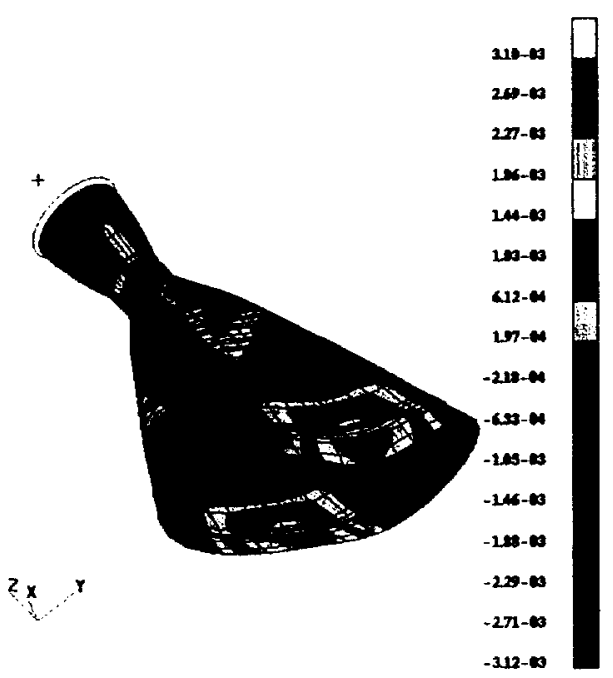

Figure 4. 2 Nodal Diameter Mode Shape at $58.1 \mathrm{hz}$ predominance of the nozzle $2^{\mathrm{ND}}$ mode (Fig. 4) in the time histories and circumferential strain map at the peak loading time point (Figure 5). Using the correlated structural dynamic model of the nozzle and a hypothesized mechanism of excitation being that of a onesided impact load in phase with the $2^{\mathrm{ND}}$ mode, a magnitude of loading for this mechanism was generated. At this point, however, it was clear that significant further testing, study, and analysis was required to accurately characterize the fluid/structure interaction phenomena and to produce useful design and analysis methodologies. To this end, a MSFC internally funded research and development program was initiated during 2000.

\section{Design and Manufacture of Sub-Scale Nozzles}

Based on the literature survey and previous experience of members of the research project team, a decision was reached to design, build and test two nozzles, one with a thin, flexible wall that would exhibit potential fluid/structure interaction and the accompanying resonant magnification of the pressure forces, and another with a thick, rigid wall that would provide a baseline for internal pressure measurements. These requirements called for building sub-scale nozzles to be tested in the MSFC cold-flow Nozzle Test Facility (NTF), where pressure and structural strain measurements can be obtained simultaneously. The literature indicates that this is the first time a "flexible" sub-scale nozzle has been tested in such a facility. The successful design of the nozzle required analytical sub-scale nozzle models, attention to details such as pressure transducer plug design and location, and application of advanced manufacturing techniques for thin-walled structures. Several different types of contours were evaluated, with the final choice based on an "ideal" rocket nozzle contour. In addition, an extensive structural analysis also was required on the thin-wall nozzle both to identify locations of expected maximum strain for placement of the strain gages and to prove that the nozzle would be strong enough to withstand expected loadings. An extremely high fidelity model was created and both static and 

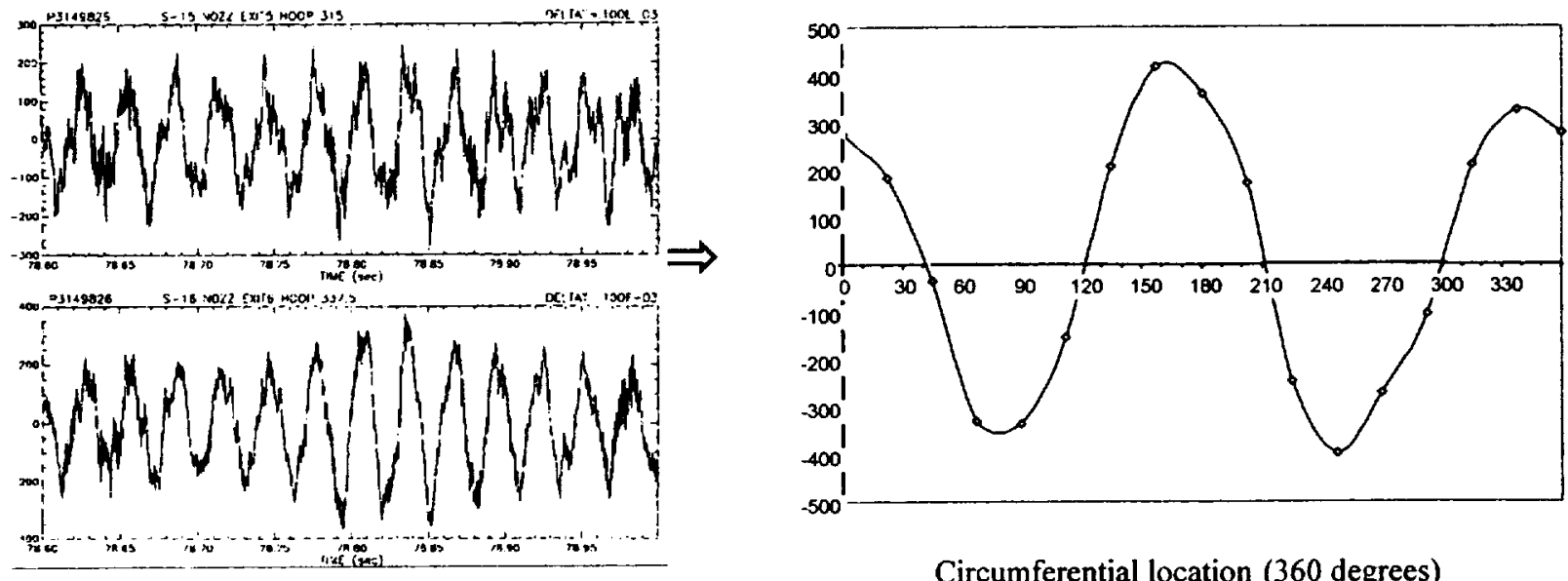

Circumferential location (360 degrees)

Figure 5. Microstrain Data from FASTRAC Nozzle Test

dynamic analysis was performed and documented" Strain "red-line" conditions were also determined using this model to ensure safe testing in the NTF.

The nozzles were fabricated in about 4 months and delivered to MSFC in June 2001. A photo of the 26.7 " long by 12.4 " exit diameter thin-wall nozzle is shown in Figure 6 . The pressure port final configuration consisted of two sets of taps able to house either static or dynamic pressure gauges distributed axially along the length of the nozzle (stations 1-17) while two other sets of taps were distributed circumferentially at two separate (nearthroat and near-exit) axial locations (11A-11H and $16 \mathrm{~A}-16 \mathrm{H})$. Because the ports required at least half an inch of material to thread into, this required that two "ribs" be built into the thin-wall nozzle at the two main circumferential locations and "islands" be build to house the other ports.

\section{Hot-Fire Data From MC-1 Engine}

While the nozzles were being designed and

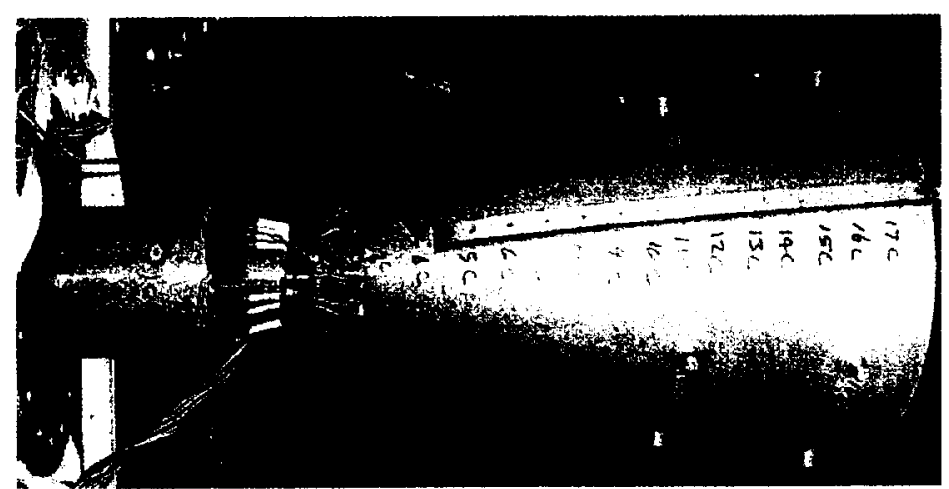

Figure 6. Thin-wall sub-scale nozzle showing ports \& strain gages manufactured, a simultaneous effort to obtain additional hot-fire data was undertaken. Some data was obtained when approval was given to make strain gage measurements for hot-fire testing of the 30:1 nozzle on the MC-1 engine for engine 5, which was tested in late October 2000. Initial examination of the data was required to locate a high-strain event suitable for analysis. Time histories, circumferential strain mappings, and power spectral density (PSD) measurements of the strains during this 0.3 -second interval were then created and examined (Figures 7). This data clearly shows the predominance of the $2^{\mathrm{ND}}$ mode, which was identified via a finite element analysis of a system model of the MC-1 engine. These results are not conclusive evidence of a fluid/structure interaction, though, since the random combustion process itself will excite all the structural modes. Measured acceleration data from the combustion chamber, therefore, was obtained from the same MC-1 test and applied as a dynamic input onto the system model, and PSD's of strains at the same locations as those measured were analytically determined. These PSD's were compared with the measured PSD's and the resulting different spectral composition of the analytical results indicates that the predominance of the measured $2^{\mathrm{ND}}$ mode would not be expected from just the expected excitation from the combustion process. It should be noted though, that only the orthogonal accelerations resulting from combustion were applied as excitations, not the random shape of the actual combustion fluid forcing function, so this difference may alter this conclusion since it may be difficult for a purely transverse excitation to excite the $2^{\mathrm{ND}}$ mode. Similar measurements necessary to complete a statistically valid database 


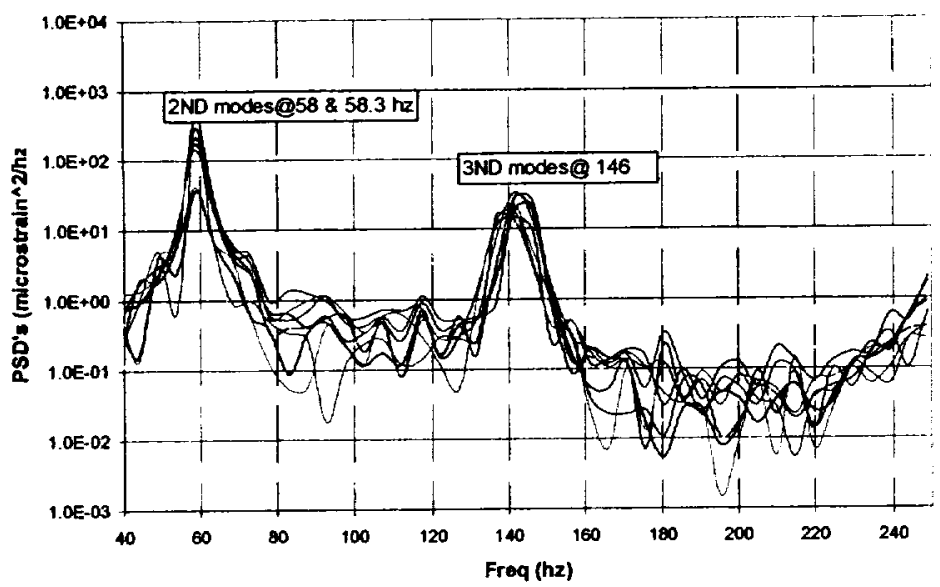

Figure 7. Measured Hoop Strain PSD's near Exit Plane from MC1(30:1) Hot-Fire

were planned from planned additional MC-1 testing, but that program was cancelled.

\section{Sub-Scale Nozzle Testing}

In the meantime, a test matrix for the cold-flow testing of the sub-scale nozzles was created that would explore as many different combinations of chamber and ambient pressure as possible. This would allow determination of separation as a function of all possible nozzle pressure operation scenarios. The nozzles were inspected and installed at the facility shortly after delivery, and checkout tests were initiated. Extremely large facility vibrations were seen in these tests, so an extensive investigation of the facility was undertaken. This investigation included modal testing and dynamic modeling of the facility as well as experimentation with various facility modifications ${ }^{18}$. The final result was that all the load cells measuring net thrust and net side load had to be removed due to potential failure from the large vibrations, which seemed to be caused by a

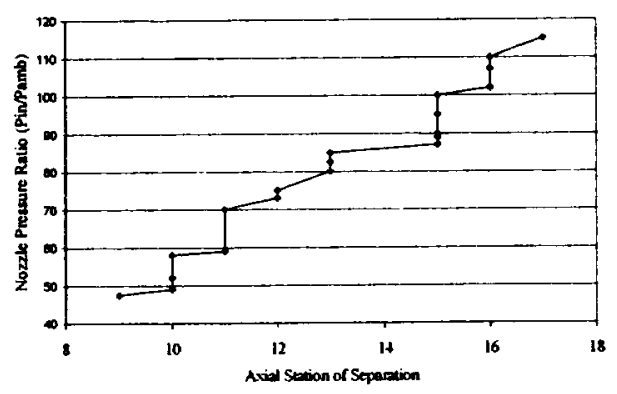

Figure 8. Appproximate Separation location vs. NPR combination of the large thrust of the sideload nozzles and facility design issues. Although the lack of load cell data prevented the calculation of a net side load, and there were additional "base" vibrations to the nozzle other than those anticipated, the primary data requirements of the tests (pressure and strain gage data), were not affected significantly, so the test program was not severely compromised.

The test program itself proceeded very rapidly, and has been documented in detail $^{19}$. The thick-wall nozzle was tested first, and separation over much of the axial range of the nozzle was obtained, yielding an approximate relationship with nozzle pressure ratio (NPR), which is chamber pressure divided by ambient pressure, as shown in Figure 8. The data for this test is presently being examined in detail, and is being used to produce a methodology for determining the location of separation and magnitude of fluid excitation due to the separation. This methodology will serve as a bounding condition for rigid nozzles when there is no structural interaction with the pressure field, and will be described in a future paper by the authors.

The thin-wall nozzle was then installed, and as anticipated, the magnitude of the fluid loading was large enough to cause easily measurable structural response of the nozzle. During test run 373 , which had an inlet pressure of $180 \mathrm{psi}$ and an NPR of 110 , the nozzle response reached the red line limit and the test was halted. The test was captured on videotape as well as by the pressure, accelerometer, and strain gauge instrumentation, and shows what is apparently a very large self-excited vibration likely caused by a feedback loop. Extensive data examination is being performed to explore the character of the fluid field and the structural response.

\section{Data Analysis}

The first step in the data analysis is to characterize the structural response. The predominant frequency

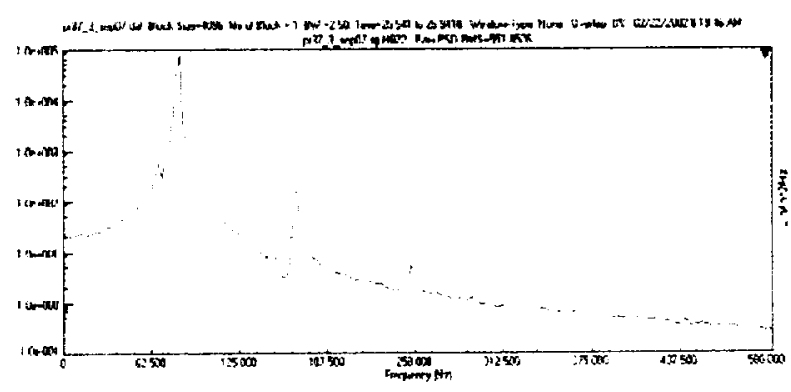

Figure 9. PSD of Hoop Strain Gauge at $22^{\circ}$ during Highest Resbonding Time Segment 

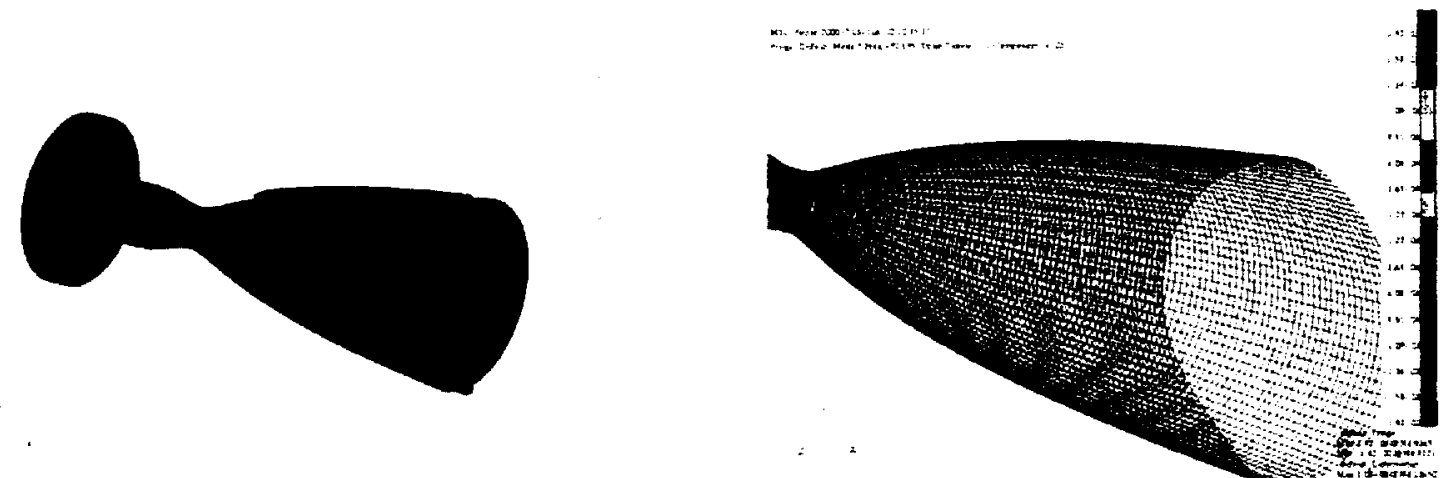

Figure 10. Model of Thin Wall Nozzle, deformed $2^{\mathrm{ND}} \mathrm{b}$ mode shape with outer surface strains at strain gage locations

observed during run 37 is around $82 \mathrm{hz}$, as shown in Figure 9, which shows a PSD of one the strain gauges. This frequency corresponds to the second $2^{\mathrm{ND}}$ mode $\left(2^{\mathrm{ND}} \mathrm{B}\right)$, where the oscillation peaks (antinodes) occur at a $45^{\circ}$ angle from the vertical axis of the nozzle (Figure 10). This correspondence is verified by Figure 11 , which show the response of all the strain gages at a single instant for a $180^{\circ}$ segment. The response of two accelerometers at the exit plane of the nozzle show a higher response at $162 \mathrm{hz}$, which is close to the predicted to the $3 \mathrm{ND} /$ first bending mode. This indicates that the response is a combination of the $2^{\mathrm{ND}} \mathrm{B}$ and the $3^{\mathrm{ND}}$ modes, but since the accelerometers are located at the nodes of the $2^{\mathrm{ND}} \mathrm{B}$ mode, a low response at that modal frequency would be expected. A structural dynamic analysis of the nozzle for a orthogonal base random excitation (using acceleration data measured at the inlet flange) shows that the $3^{\mathrm{ND}}$ /first bending mode is the predominant responding mode, so this combination is expected.

Using this information, an estimation of the entire displacement shape of the nozzle during these high oscillation events can be made. Assuming the entire nozzle vibrates in the $2^{\mathrm{ND}} \mathrm{B}$ mode shape, the normalized modal displacement is scaled by a factor

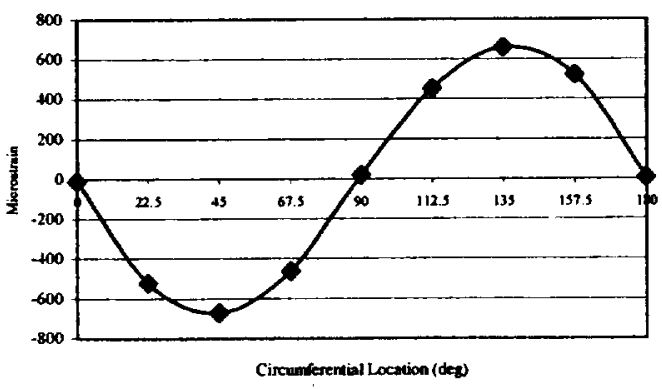

Figure 11. Strains at $28.8 \mathrm{sec}$, Thin wall Nozzle Run 373 of the measured strain gages divided by the analytical finite element modal strains in the same location. This factor is

$$
\frac{1332 \text { maximum measured } \mu \text { strain }}{1820 \text { modal } \mu \text { strain }}=0.731 .
$$

Since the peak radial modal deformation is 1.0 " at the exit, this factor implies that the actual peak deformation is 0.731 ".

This value appears to be too large compared with examination of the video. For a first-cut analysis, though, the trends can be examined by using a magnitude of $20 \%$ of the predicted maximum value in a $2-\mathrm{D}$ flow model of the nozzle. For this analysis, 2-D axial slices of the nozzle in its assumed deformed position at different circumferential locations are applied quasi-statically to determine the pressure variation. Preliminary results for the internal pressure field, separation locations (using an assumed critical separation value), and integrated net force on these 2-D sections of the nozzle are shown in Figure 12 and 13 . Figure 12 shows the pressure field, where $0^{\circ}$ is the section of maximum deflection and $90^{\circ}$ is the section of minimum deflection. The analysis shows that this small change in pressure potentially drives the separation point over an inch axially due to the small gradient in the wall pressure. Figure 13 shows the total integrated force over the nozzle from the throat to the exit for different circumferential locations. This plot verifies that the pressure change as hypothesized would cause a set of forces that would deflect the nozzle into the oval shape.

This analytical correlation can then be compared with the unsteady pressure gage measurements. In addition, correlation of this data with the strain gage response can be used to examine the potential link between the deflection shape and the pressure field. Initial examination of the data shows a clear correlation of the pressure data to the $2^{\mathrm{ND}} \mathrm{B}$ frequency at $82 \mathrm{hz}$ (e.g. gage 


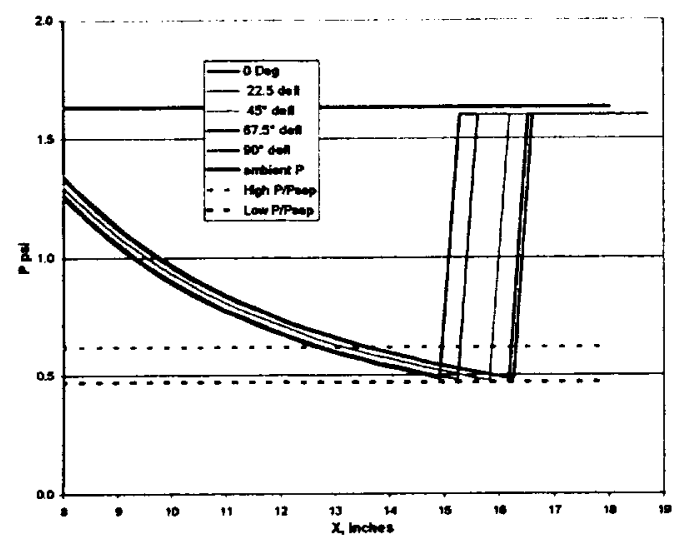

Figure 12. Predicted Sub-Scale Wall Pressure For $2^{\mathrm{ND}}$ B Mode Operating Deflection Shape

$16 \mathrm{D}$ at $135^{\circ}$ shown in figure 14). This can be compared with data from the thick wall test for the exact same conditions (run 32_1), which shows essentially random behavior in the time history and PSD of same pressure gage (figure 15). Since pressure gages are sensitive to acceleration, though, the veracity of this data has to be checked by estimating the magnitude of this sensitivity. Again, if the operating deflection is assumed to match the $2^{\mathrm{ND}}$ $B$ mode shape, the radial displacement at pressure gage $16 \mathrm{D}$ can be calculated by multiplying the scale factor determined above, 0.731 , by the normalized modal displacement at that location, $.814^{\prime \prime}$, yielding a maximum displacement of 0.595 ". Using the relationship (for this assumption of a purely $82 \mathrm{hz}$ response),

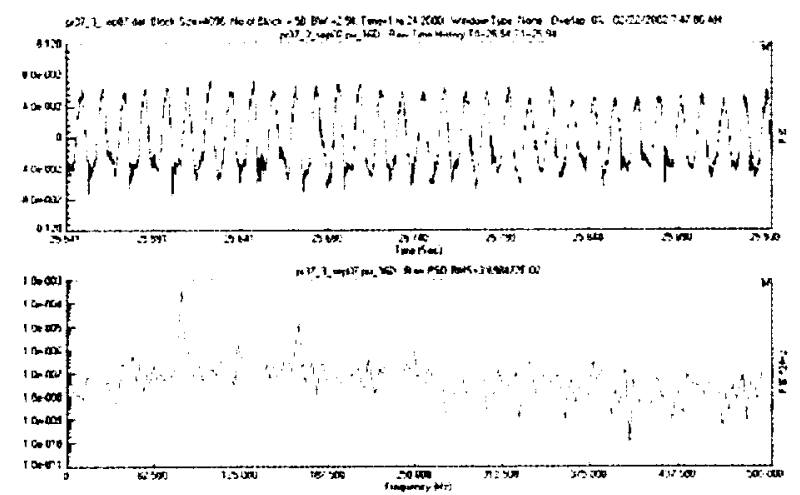

Figure 14. Pressure gauge $16 \mathrm{D}$, thin wall nozzle run 37 3

$$
\ddot{x}=\omega^{2} x
$$

an acceleration can be estimated to be $409 \mathrm{~g}$ 's. The maximum calibrated sensitivity of the pressure gages toacceleration is $.0003 \% / \mathrm{g}$ of full scale (25 psi), yielding a maximum possible sensitivity for this case of 0.03 psi. The measured amplitude for gage $16 \mathrm{D}$ is $.05 \mathrm{psi}$, and, using the analytical fluid model described above, the amplitude of attached-wall pressure variation is calculated to be 0.041 psi. Because of the large relative size of the acceleration error, it is difficult to isolate the actual pressure variation from the error for correlation with analysis.

An additional confusing factor in the examination of the attached-wall pressure data is identified when it is seen that the pressures are in-phase with the strain gages (figure 16). This is counter to the hypothesis and the

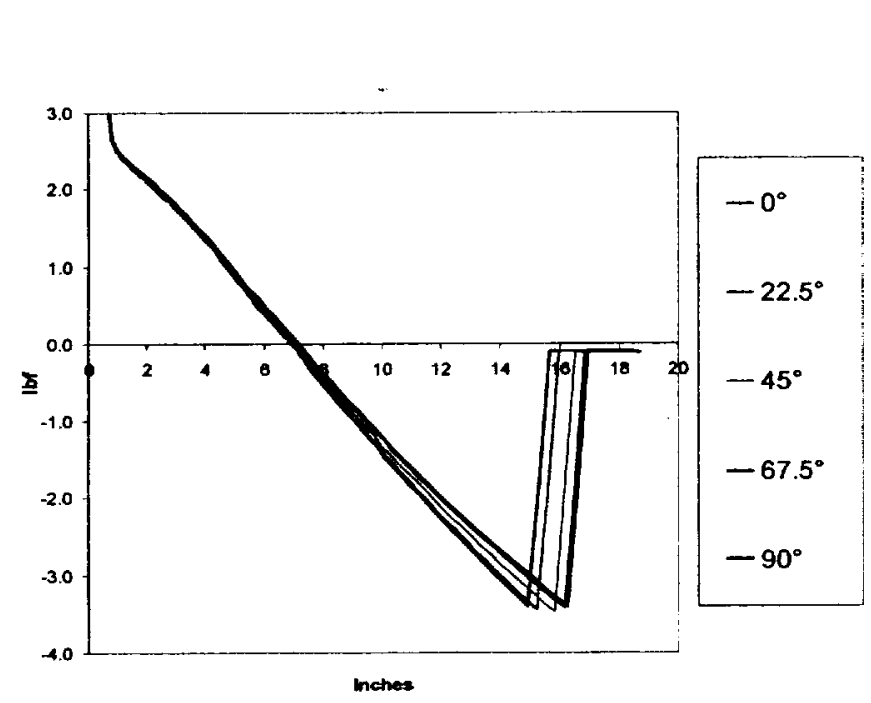

a)

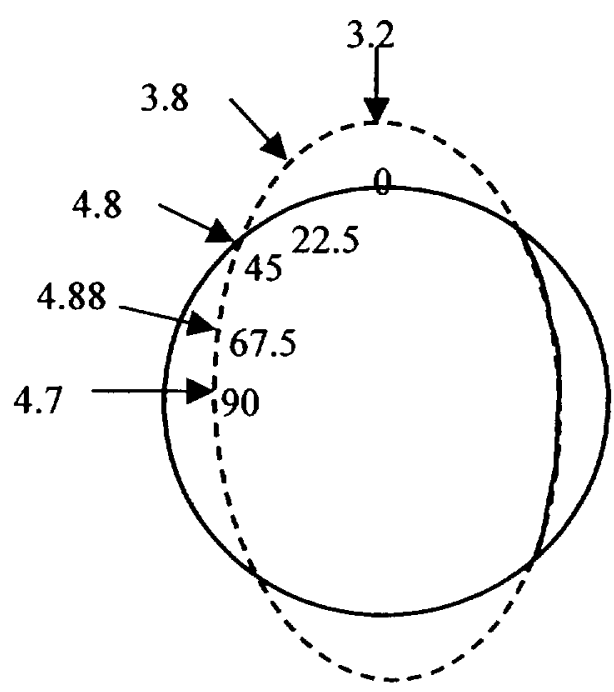

b)

Figure 13. a) Integrated Radial Force (lb)/unit length/degree from throat to exit b) Total Integrated Force at different Circumferential Locations

American Institute of Aeronautics and Astronautics 


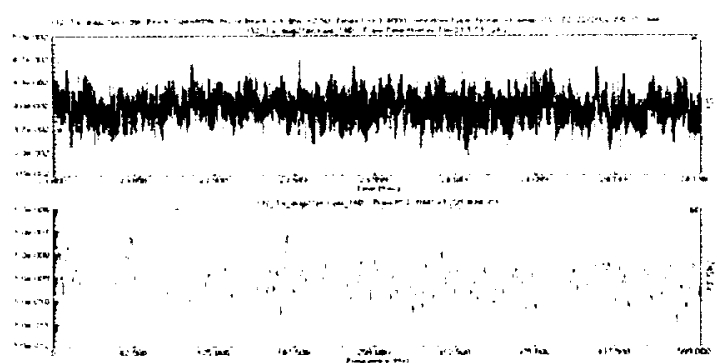

Figure 15. Pressure gauge 16D, thick wall nozzle run 32 la

analysis which indicate that the pressures should be out-of-phase with the gages. On the other hand, since these pressure oscillations are in-phase with the strain gages, any separation occurences, which will appear as sudden pressure spikes, can be easily tied to the phase of the strains. A notable observation can be drawn by applying this fact to the data shown in figure 17. Separation is shown to be occurring directly over the pressure gage $16 \mathrm{D}^{\circ}$ since it shows only a few spikes while the separation an inch downstream at station $17 \mathrm{C}$ is much more pronounced. The spikes are seen to occur at the peak of each small pressure wave, and are therefore in resonance with the $2^{\mathrm{ND}} \mathrm{B}$ mode seen in the strain data, which does agree with the hypothesis of the feedback vibration. Additionally, if the $16 \mathrm{D}$ pressure is overlaid by the pressure at station $16 \mathrm{~F}$ (see figure 18 ), which is at $90^{\circ}$ away at $225^{\circ}$, it is seen that the separation spikes at $16 \mathrm{~F}$ are out-of-phase with $16 \mathrm{D}$, which also supports the connection of the separation with the modal vibration.

Other runs have also been examined for high levels of harmonic vibration. The highest one found has been run 353 , which also has a NPR of 110 but has a chamber pressure of 100 psi. As with run 37 , the strain gages clearly indicate a response at the $2^{\mathrm{ND}}$
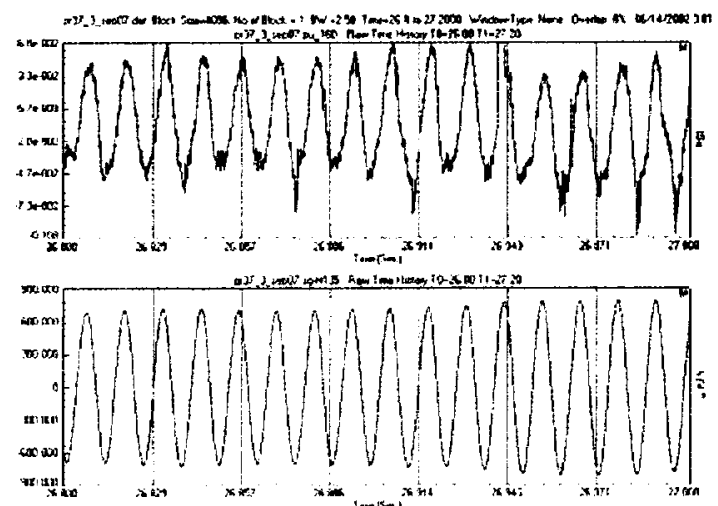

Figure 16. Pressure gage at station $16 \mathrm{D}\left(135^{\circ}\right)$ with strain gage at same circumferential location

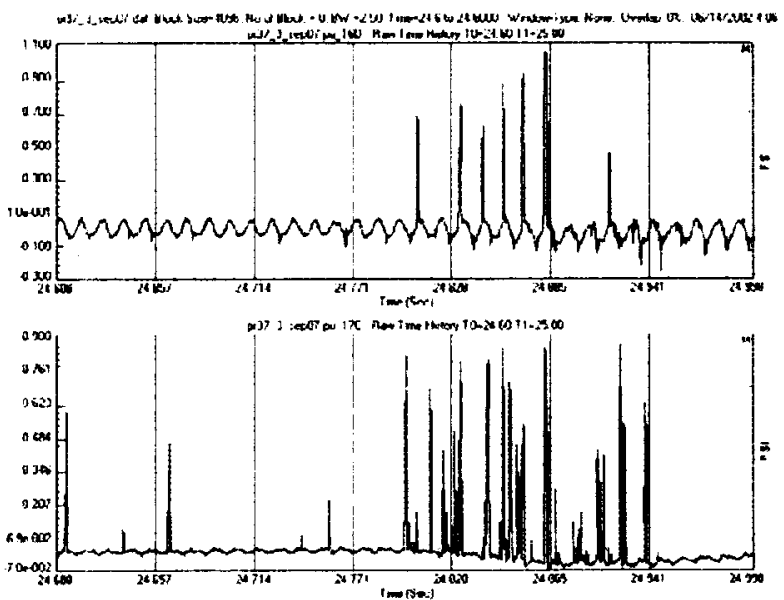

Figure 17. - Time segment of dynamic pressure gages at station $16 \& 17$

B mode (fig. 19), and the separation spikes are also dominated by that frequency and are in-phase with the strain gages. Other test runs show results similar to run $34 \_2$, which has a chamber pressure of 50 psi with a NPR of 91 . This case shows significantly smaller levels of strain gage response $(\sim 130 \mu$ strain), and is still strongly harmonic at a frequency of around $85 \mathrm{hz}$. Separation is clearly indicated in the steady and dynamic pressure data at an axial location somewhere between stations 14 and 16. However, no periodicity is indicated in either the separation spikes or the pressure data, but this may be due to the fact that the only pressure gage at station 14 is at $90^{\circ}$, which, as mentioned earlier, is at the node of the $2^{\mathrm{ND}}$ $B$ mode.

\section{Conclusions and Future Work}

The full scale and sub-scale nozzle testing described in this paper show evidence of resonant excitation of the $2^{\mathrm{ND}}$ "bell" mode in the strain data and in test video for a particular range of nozzle pressure ratios. The mechanism for this response is presently being sought through further examination of the data and numerical simulation, but appears to be caused by a self-excited vibration loop tying the structural mode and flow separation. The improved methodology presently being developed by the authors for defining the separation location using the thick-wall nozzle data should also be useful in defining the mechanism. Once this technique is formulated, an aeroelastic response analysis similar to that identified by Pekkari can be applied and checked against the data. If verified, this procedure can then be applied for future designs. In addition, a study into the statistical variability of the data will be initiated. 
p137_3_sep07.dat, Block Sze=4096, No of Block =0.999999, BW =250, Time=24.6 to 25, Window-Type: None, Overka: 0\%, 07/04/2002 3:58:17 PM

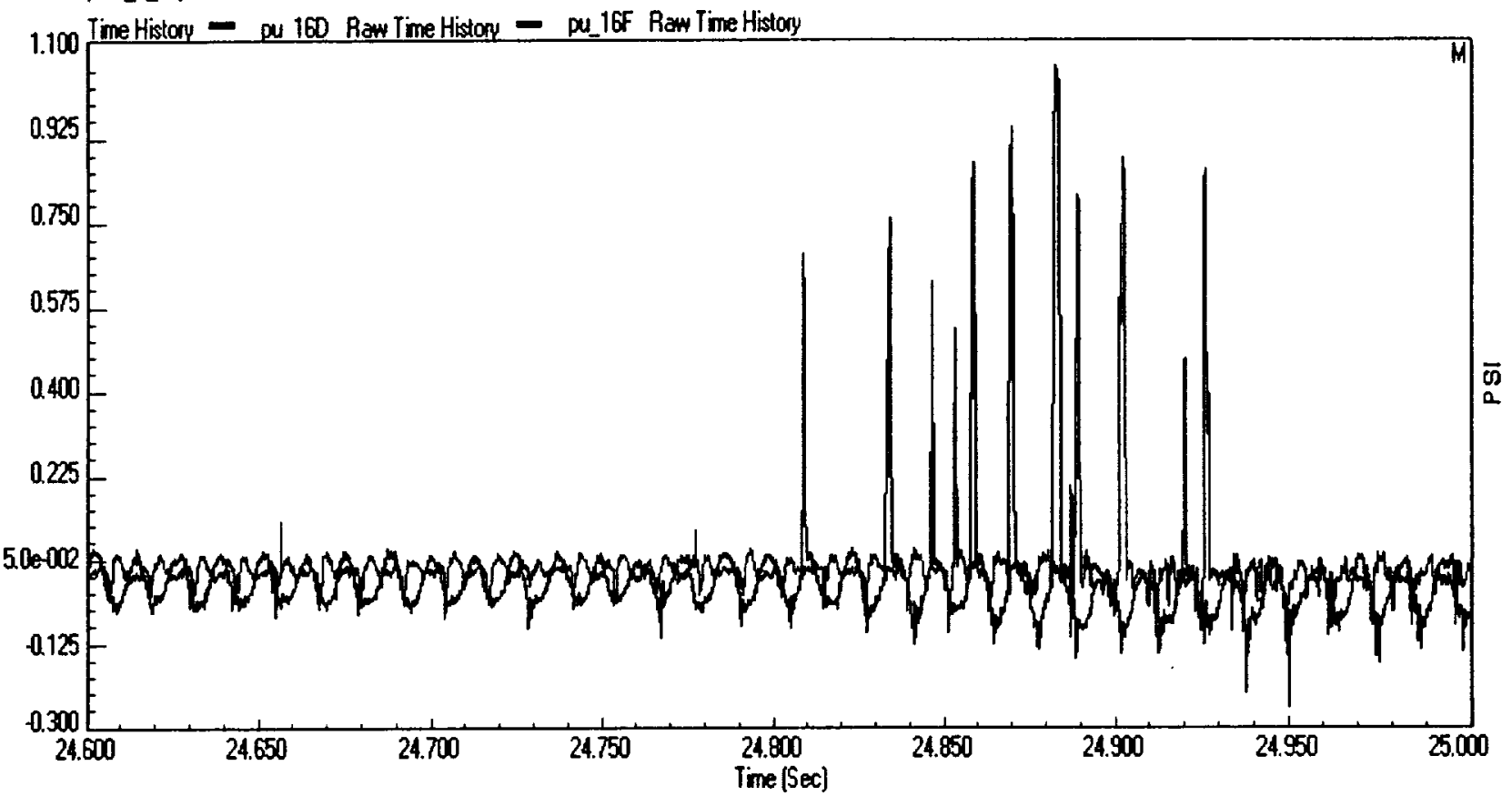

Figure 18. Pressure gauge 16D (dark), 16F(light) from thin wall nozzle run 37 _3

Additional sub-scale testing may be possible which would allow several improvements. These include the placement of a fiber optic inserted downstream of the exit normal to the exit plane, which may be able to more clearly capture the radial displacements for use in the fluid analytical model. Further testing also would take advantage of the lessons learned here to obtain more optimal instrumentation placement and specific test condition dwell time. It is anticipated that useful techniques for predicting side loads for analysis and rocket engine design will be a final product of these studies.

\section{Acknowledgements}

This program was funded under the NASA/MSFC Center Directors Discretionary Fund for fiscal years 2000 and 2001 . Continuing efforts are supported as part of the Space Launch Initiative program. Appreciation is extended to the Bill Kilpatrick, manager of the Engineering Directorate, for his sponsorship.

\section{References}

${ }^{1}$ Foster, C. R. and Cowles, F. B., "Experimental study of gas flow separation in overexpanded nozzles for rocket motors," Calif. Inst. Tech. Progr. Rept. 4-103 (1949).
${ }^{2}$ McKenney, J. D., Ae. E. Thesis, Calif. Inst. Tech. (1949).

${ }^{3}$ Summerfield, M., Foster, C. R., and Swan, W. C., "Flow separation in overexpanded supersonic exhaust nozzles," Jet Propulsion, Vol. 24, pp. 319-21 (1954).

${ }^{4}$ Arens, M. and Spiegler, E., "Shock-induced boundary layer separation in overexpanded conical exhaust nozzles," AIAA J., Vol. 1, pp. 578-581 (1963).

${ }^{5}$ Lawrence, R. A., "Symmetrical and unsymmetrical flow separation in supersonic nozzles," Ph.D. Thesis, Southern Methodist University (April, 1967).

${ }^{6}$ Schmucker, R., "Flow processes in overexpanded nozzles of chemical rocket engines" (in German), Rept. TB-7,-10,-14, Technical University of Munich (July, 1973).

'Rocketdyne Engineering, "J-2S Nozzle Side-Load Study Final Report", Contract NAS8-25156, Report R-9045 (August 1972).

${ }^{8}$ Rocketdyne Engineering, "SSME Program Engine Side Loads Study", RSS-8334 (June 1971). 

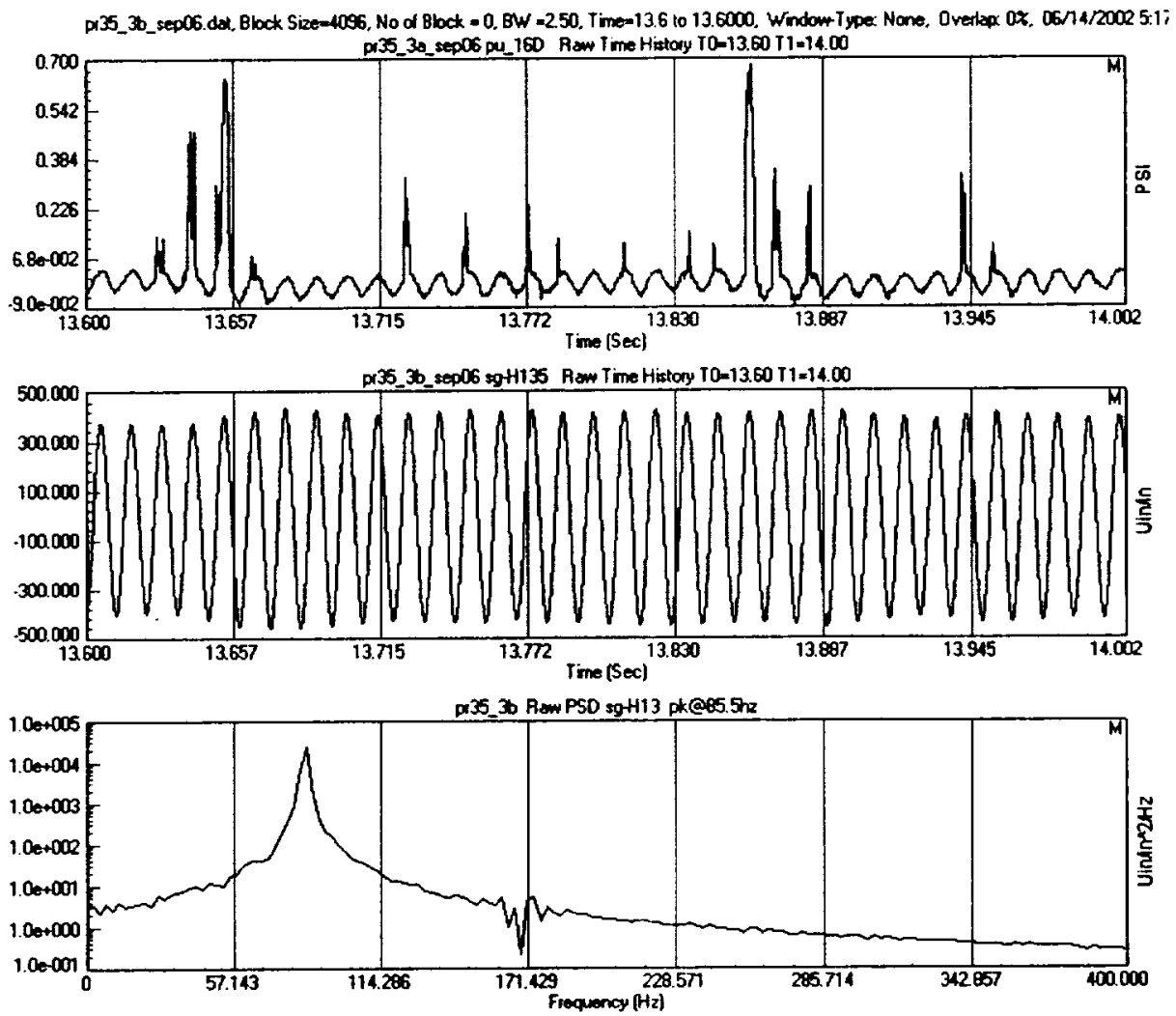

Figure 19. Strain and pressure gage data showing dominance of $2^{\mathrm{ND}}$ mode @ 85 $\mathrm{hz}$ and phase relationship with separation spikes

'Frey, M. and Hagemann, G., "Status of flow separation prediction in rocket nozzles," AIAA paper 98-3619, presented at the 34th AIAA/ASME/SAE/ASEE Joint Propulsion Conference, Cleveland, OH (July, 1998).

"Onofri, M. and Nasuti, F., "The physical origins of side loads in rocket nozzles," AIAA paper 99-2587, presented at the 35th AIAA/ASME/SAE/ASEE Joint Propulsion Conference, Los Angeles, CA (June, 1999).

${ }^{12}$ Hagemann, G., Terhardt, M., Frey, M., Reijasse, P., Onofri, M., Nasuti, F. and Ostlund, J., "Flow separation and side-loads in rocket nozzles," presented at the 4th Intl. Symp. Liquid Space Propulsion, DLR Lampoldshausen (March, 2000).

${ }^{13}$ Terhardt, M., Hagemann, G. and Frey, M., "Flow separation and side-load behavior of the Vulcain engine," AIAA paper 99-2587, presented at the 35 th AIAA/ASME/SAE/ASEE Joint Propulsion Conference, Los Angeles, CA (June, 1999).
${ }^{10}$ Chen, C.L., Chakravarthy, S. R. and Hunh, C. M., "Numerical investigation of separated nozzle flows," AIAA J., Vol. 32, pp. 1836-1843 (1994).

${ }^{14}$ Holland, W., "SSME/Side Loads Analysis For Flight Configuration," NASA TM X-64841, Rev. A, Sep. 1974.

${ }^{15}$ Rockwell International/Rocketdyne Division, "RS-27 Predicted Side Loads for New Nozzle Design, " Rockwell IL 1128-3069, SSME 81-1541, 12 Oct. 1981.

${ }^{16}$ Pekkari, L.-O, "Aeroelastic Analysis of Side Load in Supersonic Nozzles with Separated Flow," AIAA paper 94-3377, $30^{\text {th }}$ AIAA/ASME/SAE/ASEE Joint Propulsion Conference, Los Angeles, CA (June, 1994).

${ }^{17}$ Poole, E., "Sub-Scale Nozzle for Side-Loads Testing Structural Assessment Report", memo \# ED22-01-099, NASA Marshall Space Flight Center, Strength Analysis Group/ED22, June 14, 2001

${ }^{18}$ Driskill, T., "Sub-Scale, Thin-wall Nozzle and Nozzle Test Facility Modal Surveys," Memo \# ED27-01-081, August 14, 2001

10

American Institute of Aeronautics and Astronautics 
${ }^{19}$ Snellgrove, L., Characterization and Accurate Modeling of Rocket Engine Side Loads Nozzle Air Flow Test Post Test Report, Test Number P2223," NASA Marshall Space Flight Center, TD63, November 5, 2001 